\title{
Quantitative Weld Quality Acceptance Criteria: An Enabler for Structural Lightweighting and Additive Manufacturing
}

\author{
Recent developments in fracture-mechanics based defect acceptance criteria, as \\ well as robust computational techniques, are higlighted
}

BY P. DONG

\begin{abstract}
Most of the existing weld quality acceptance criteria stipulated in various codes and standards, as well as in recommended practices, are empirical in nature. Historically, these workmanship-based criterias have been adequate for quality control purposes in construction of welded structures. However, as the competition for achieving structural lightweighting intensifies, more quantitative quality acceptance (also known as fitness-for-purpose based) criteria are increasingly called for. This is because various new forms of discontinuities and joint configurations (e.g., dissimilar materials joints) cannot be readily related to existing acceptance criteria. Even if existing criteria can be made applicable, recent research findings have shown that existing criteria can be excessively conservative for some and unconservative for others when dealing with thin gauge and lightweight construction. A similar situation exists for additively manufactured metallic components, which can be viewed as "all weld metal" components containing randomly distributed discontinuities over the entire component volume. In this paper, some of the recent developments in quantitative weld quality acceptance criteria will be first highlighted, some of which are made possible by advanced fracture mechanics analysis techniques. Applications in structural lightweighting and additive manufacturing will then be demonstrated with some real-world examples. Finally, implications on a broader application of the methodologies presented for ensuring both structural integrity and cost-effectiveness in construction will be discussed in light of these developments.
\end{abstract}

\section{KEYWORDS}

- Weld Quality • Lightweighting • Additive Manufacturing - Applied Fracture Mechanics • Fitness-for-Purpose

- Dissimilar Metal Joining • Defect Assessment

\section{Introduction}

Various forms of geometric discontinuities or imperfections, such as pores and inclusions, are always present in welded components (Refs. 1-4) - Fig. 1A. The same can be said about other manufacturing processes like forged components (Fig. 1B), or even in plain materials, which are just a matter of length scale. In the construction of modern lightweight structures, lightweight aluminum alloys are increasingly being used in the automotive industry. Due to productivity requirements, resistance spot welds or laser welds tend to contain a more pronounced porosity, depending on materials and welding parameters used - Fig. 2 (Ref. 1).

Although friction stir welding (FSW) has many advantages over the traditional fusion welding processes, some unique discontinuity forms (such as kissing bonds and "hook-like" defects - Fig. 3) can pose significant challenges to nondestructive examination (NDE) techniques due to potential implications on the structural integrity of such joints if missed in production. As 3D printing (or additive manufacturing $[\mathrm{AM}]$ ) gains popularity in the metal manufacturing industry, quality acceptance criteria have become one of the key technological hurdles for the adoption of safety-critical applications. AM parts' "all weld metal" nature in terms of randomly distributed discontinuities over a bulk build is illustrated in Fig. 4 for a 3D printed Ti-6-4 round bar (Ref. 5). One key question here is how to determine what level of discontinuities, both in size and distribution, is acceptable for a given product application. Similar questions have also been repeatedly asked for dealing with dissimilar metal joints such as aluminum to steel joints in which brittle intermetallic compounds typically develop, often accompanied by microcracks.

To address the questions posed above, fracture mechanics methods can be used. The power generation and petrochemical industries have widely adopted these methods as a postconstruction assessment method for demonstrating struc- 

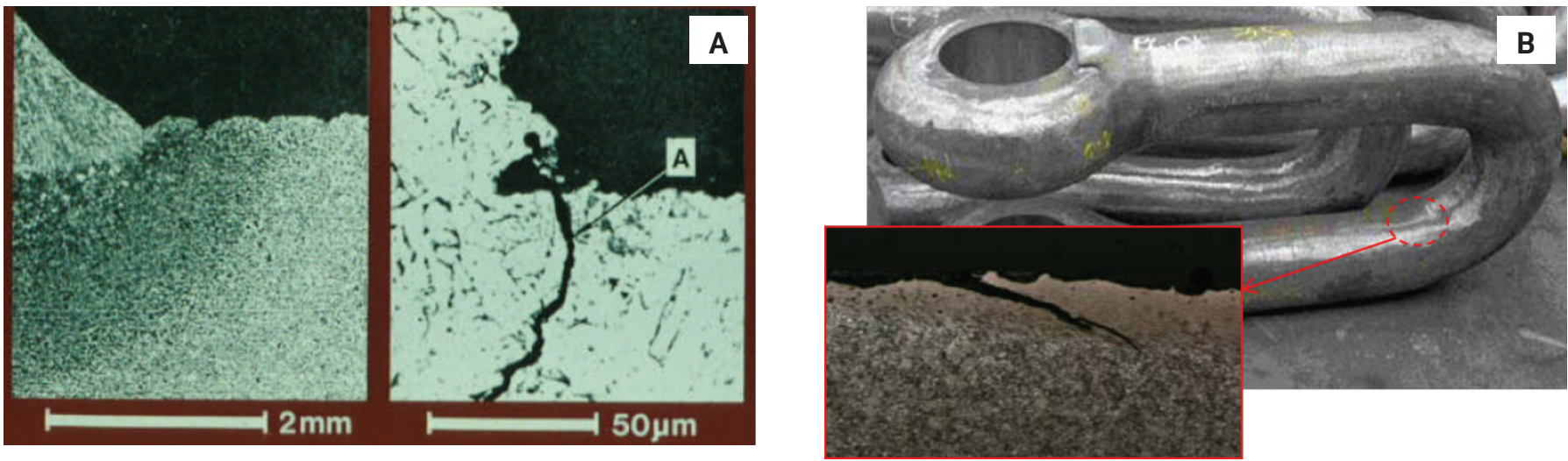

Fig. 1-Representative defects at a different length scale: A - Fillet weld; B - forged component.

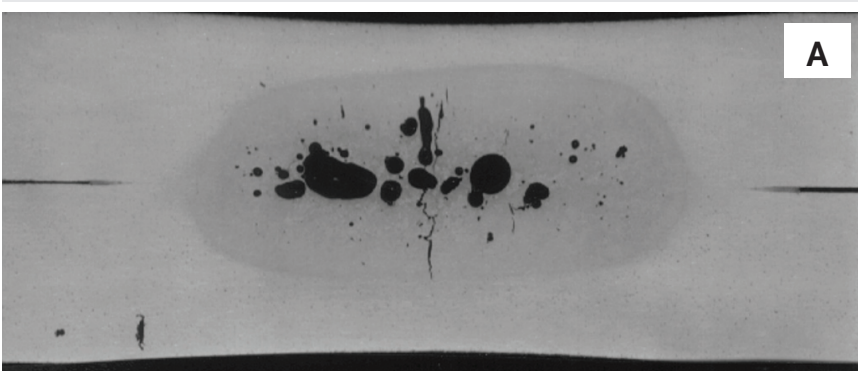

Fig. 2 - Representative defects in resistance spot welds and laser welds: A - Resistance spot weld; B - laser welds.

tures or pressure equipment's fitness for continued service when a defect (hypothetical or real) is considered (Refs. 6 and 7). These methodologies are often referred to as engineering criticality assessment (ECA) or fitness-for-service assessment procedures, representing practical application procedures as fracture mechanics continue to advance. Some of these advancements are particularly suited for applications in establishing the quality acceptance criteria discussed earlier. The paper starts with some simple illustrations on the structural significance of geometric discontinuities to show that fatigue performance is the key measure of effects of discontinuities for which fracture mechanics considerations become essential. Then, some of the relevant fracture mechanics developments are highlighted. These include both direct techniques for assessing structural significance of discrete or randomly distributed defects and an indirect method for fatigue performance evaluation of components containing various forms of discontinuities. Various real-world examples were used to demonstrate how some of the fracture mechanics techniques can be used to effectively establish quantitative quality acceptance criteria for engineering applications.

\section{Structural Significance of Discontinuities}

\section{Static vs. Fatigue Strengths}

It has been well-established in the literature that the detrimental effects of geometric discontinuities associated with typical manufacturing processes can be related to components' fatigue performance under cyclic loading conditions. As long as there is no significant load-carrying area

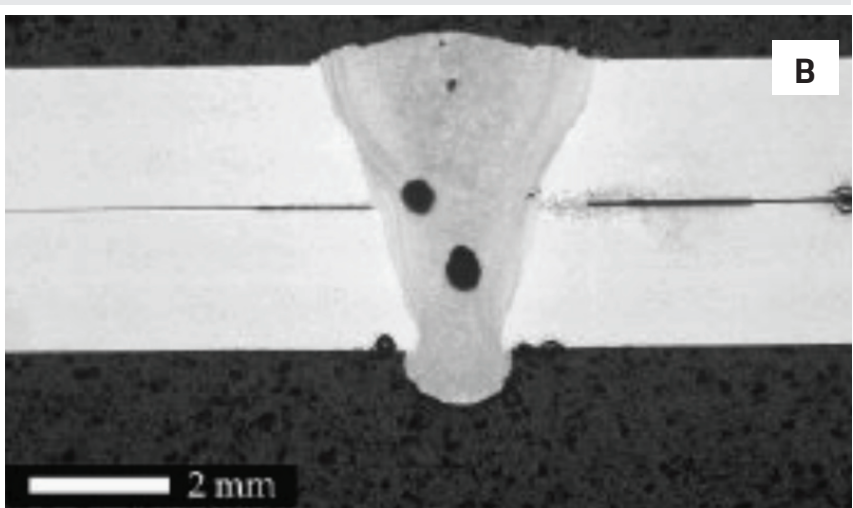

reduction, structural strengths under quasi-static loading conditions are typically not noticeably impacted. This can be clearly illustrated by considering a set of simple tension specimens containing different notch radii, resulting in different stress concentration factor $K_{t}$ (Ref. 8), as shown in Fig. 5. The resulting static strengths obtained from these tests showed essentially the same load capacity (see peak values of the load-displacement curves in Fig. 5B), even through the local stress concentration varies significantly from $K_{t}=2.5$ to $K_{t}=20$. However, the fatigue tests on two specimen types with different stress concentration factors (Fig. 6A) yield two distinct $\mathrm{S}-\mathrm{N}$ curves resulting in significantly different fatigue strengths defined by the two horizontal lines in Fig. 6B.

\section{Illustration of Quantitative Quality Acceptance Criteria}

To demonstrate the major differences between empirical based weld quality acceptance criteria and fracture mechanics based quantitative quality criteria, consider a structural steel beam welded onto a base plate as shown in Fig. 7. In traditional quality acceptance criteria, as long as any discontinuities, for example a defect size of $a_{0}$, are less than an allowable limit through a nondestructive inspection technique, a simple beam bending theory can be used to calculate maximum beam depth $H$ needed for carrying a static load $F$ without exceeding the steel yield strength $S_{Y}$, i.e.,

$$
\sigma_{\max }=\frac{M c}{I}=\frac{6 F L}{t H^{2}}<S_{Y}
$$




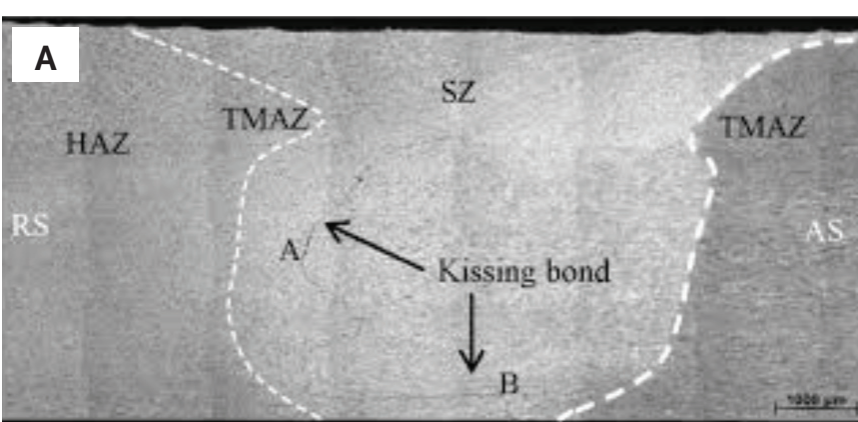

Fig. 3 - Friction stir welds of aluminum extrusions: A - View of overall friction stir zone; $B$ - local view of defects at nugget root.

Then, the beam height required can be calculated as:

$$
H>\sqrt{\frac{6 F L}{t S_{Y}}}
$$

However, the weld connecting the beam to the base may contain potential manufacturing defects that might not always be detected during a required NDE inspection due to inherent limitations in a given NDE technique. Then the question becomes: Is the beam structure still capable of carrying design load $F$ if a crack-like defect of $a_{0}$ is missed during NDE inspection? To answer this question, a fracture mechanics parameter $K_{I}$ (referred to as stress intensity factor) needs to be introduced, which relates stress in Eq. 1 to defect size $a_{0}$ in the following manner as long as $a_{0}$ is small compared to $H$ :

$$
K_{I}=\sigma_{\max } C \sqrt{\pi \alpha_{0}}<K_{I C}
$$

where $C$ is a constant. The critical condition can be determined by comparing $K_{I}$ with material fracture toughness $K_{I C}$ measured from laboratory tests. Then, for a given initial defect size $a_{0}$, we can determine the beam height requirement for carrying the required load $F$ without causing an unstable fracture by an initial defect of size $a_{0}$ :

$$
H>\sqrt{\frac{6 F L}{t K_{I C}} \times C \sqrt{\pi \alpha_{0}}}
$$

By comparing the beam height calculated from Eq. 2 and 4, the largest $H$ should be the final design height for preventing the beam both from reaching $S_{Y}$ (developing plastic deformation) and developing an unstable fracture. For defect sensitive materials, e.g., high-strength steel, Eq. 4 often prevails. This can be demonstrated by rearranging the righthand side of Eq. 3 after substituting $S_{Y}$ in place of $\sigma_{\max }$ as:
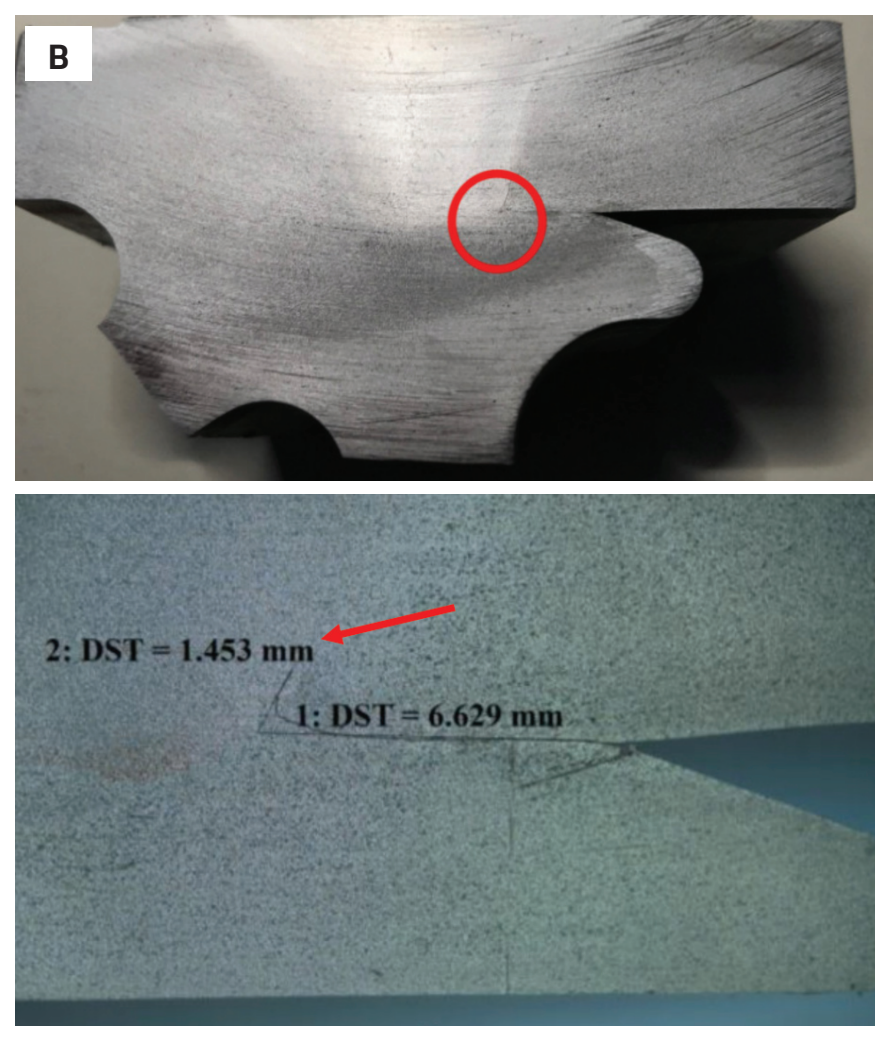

$$
\alpha_{0}<A\left(\frac{K_{I C}}{S_{Y}}\right)^{2}
$$

in which $A=1 /\left(C^{2} \pi\right)$. Although a rather simple exercise, the implications of Eq. 5 are significant as summarized in the following:

- The maximum tolerable defect is inversely proportional to the second power of material yield strength $S_{Y}$. As higher strength materials are increasingly used, the maximum tolerable defect size rapidly decreases;

-In structural metals, it is typical that as yield strength increases, fracture toughness $K_{\text {IC }}$ decreases;

- The compound effects of high yield strength and low fracture toughness make FFS or defect assessment increasingly important in manufacturing quality control, particularly modern lightweight structures.

Equation 5 illustrates that fracture mechanics not only enables a quantitative defect acceptance criterion, but it also establishes an important relationship between acceptable defect $a_{0}$ based on its significance to structural performance (in this case, propensity to brittle fracture) and other materials property (i.e., yield strength $S_{Y}$ ) in addition to fracture toughness $K_{I C}$ through Eq. 5.

\section{Advanced Applications of Fracture Mechanics Methods}

In view of the importance of fracture mechanics principles previously discussed, some of the relevant recent advances in adopting fracture mechanics principles for applications in complex structures are briefly highlighted. 

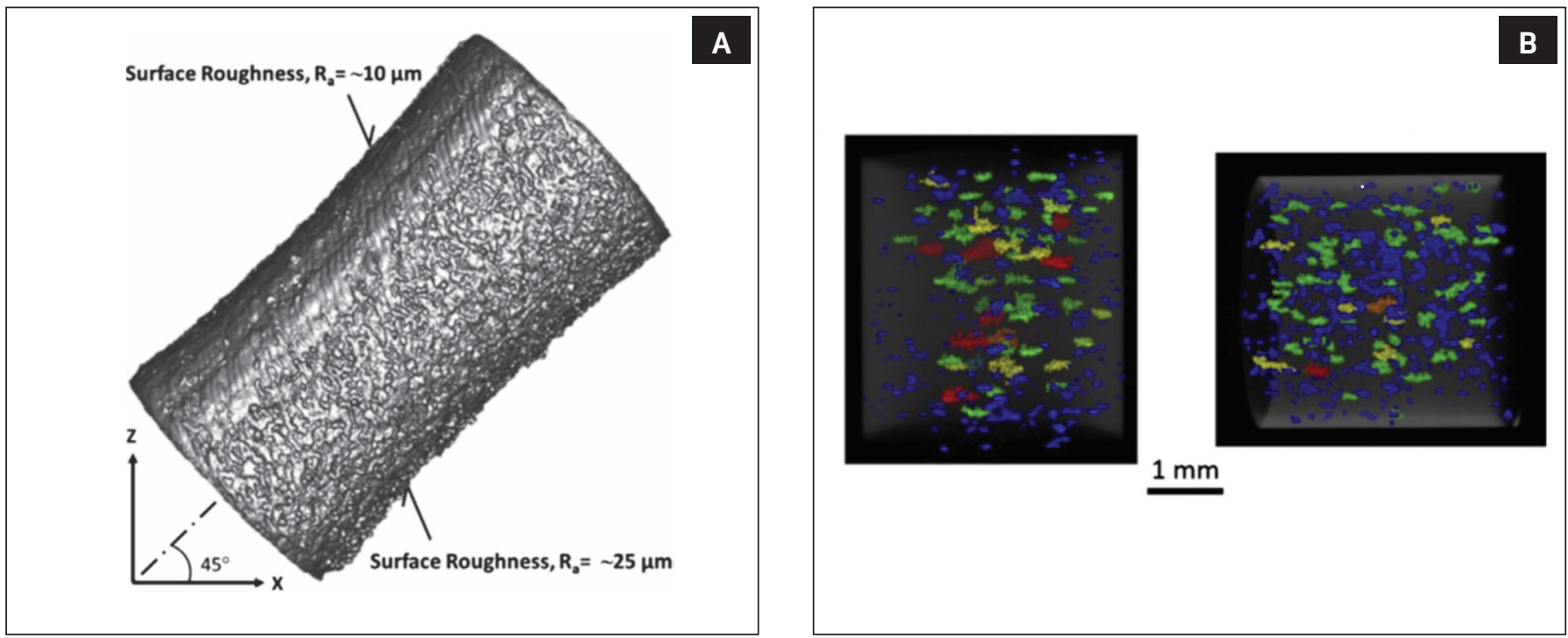

Fig. 4-Randomly-distributed discontinuities in a 3D printed titanium bar (Ti-6-4): A - Bar specimen; B - CT scan image.
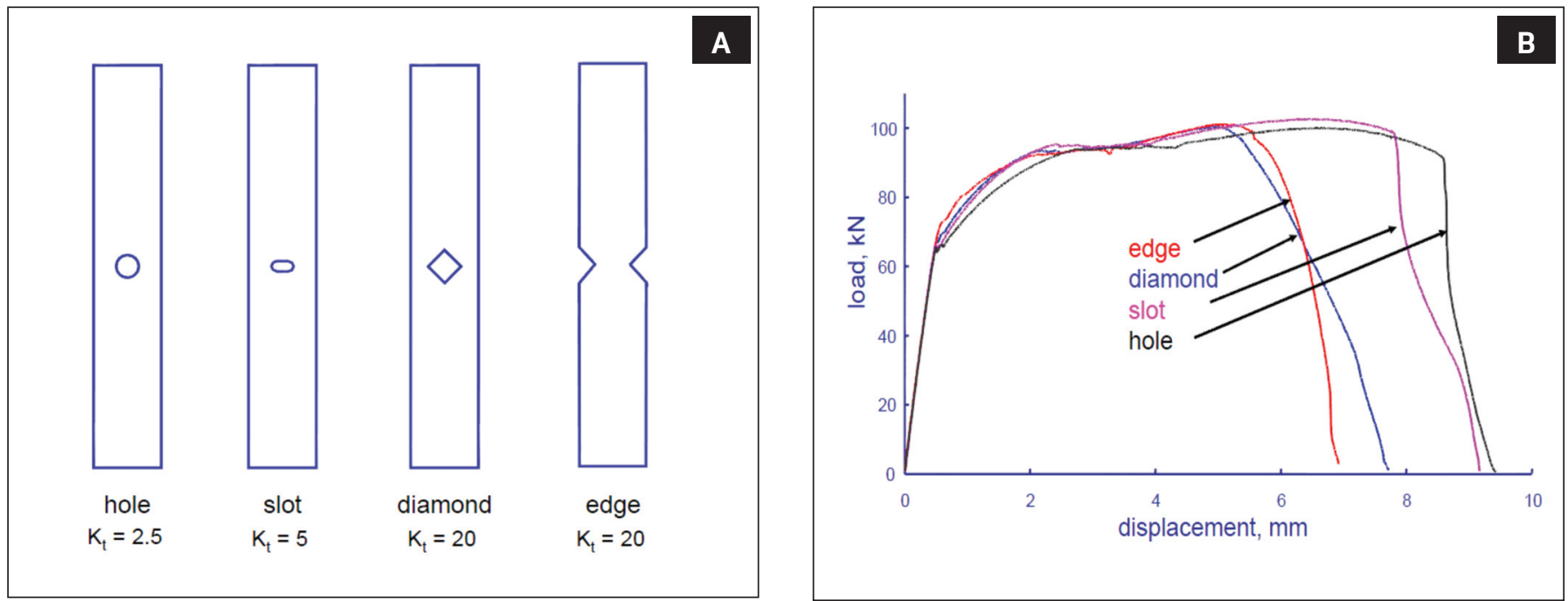

Fig. 5 - Tensile strength test results of specimens containing a varying degree of stress concentration: A - Tensile specimens containing various forms of stress concentrators; $B$ - tensile test results.

\section{Hybrid Polygonal Element (HPE) Method}

A rather novel hybrid polygonal element method was developed decades ago (Ref. 9) and has been widely used for composite materials due to its robustness for dealing with randomly distributed geometric features, e.g., cracks, inclusions, and voids. Figure 8 illustrates a thin plate containing about 27 randomly distributed cracks under remote tension. A simple polygonal element model (Fig. 8B) is all that is needed to accurately calculate stress intensity factors at each of the crack tips for all cracks. As a result, the stress intensity factor $K_{I}$ for the main crack is increased by about $200 \%$ in comparison to $K_{I 0}$ corresponding to the situation in which only the main crack is present. The maximum stress intensity factor value among all 27 microcracks occurs at Crack 17 (Fig. 8B) and is about $96 \%$ of $K_{\text {IO }}$.

This method has been adapted for performing fracture me- chanics assessment of aluminum spot welds with randomly distributed pores and microcracks, as shown in Fig. 9 (Ref. 10).

\section{Finite Element Alternating Method (FEAM)}

A finite element alternating method (FEAM) has been implemented for fracture mechanics applications in complex welded components (Refs. 11-14). This method is particularly advantageous in that it only needs a regular finite element model without the need to model the presence of a crack. It is relatively mesh size insensitive because it is based on an alternating procedure between a closed form solution for an embedded elliptical crack in an infinite body and a finite element stress solution for an actual component - Fig. 10. Its applications for modeling a variety of crack problems in welded components, including the treatment of weldinginduced residual stresses, are given (Ref. 14). 

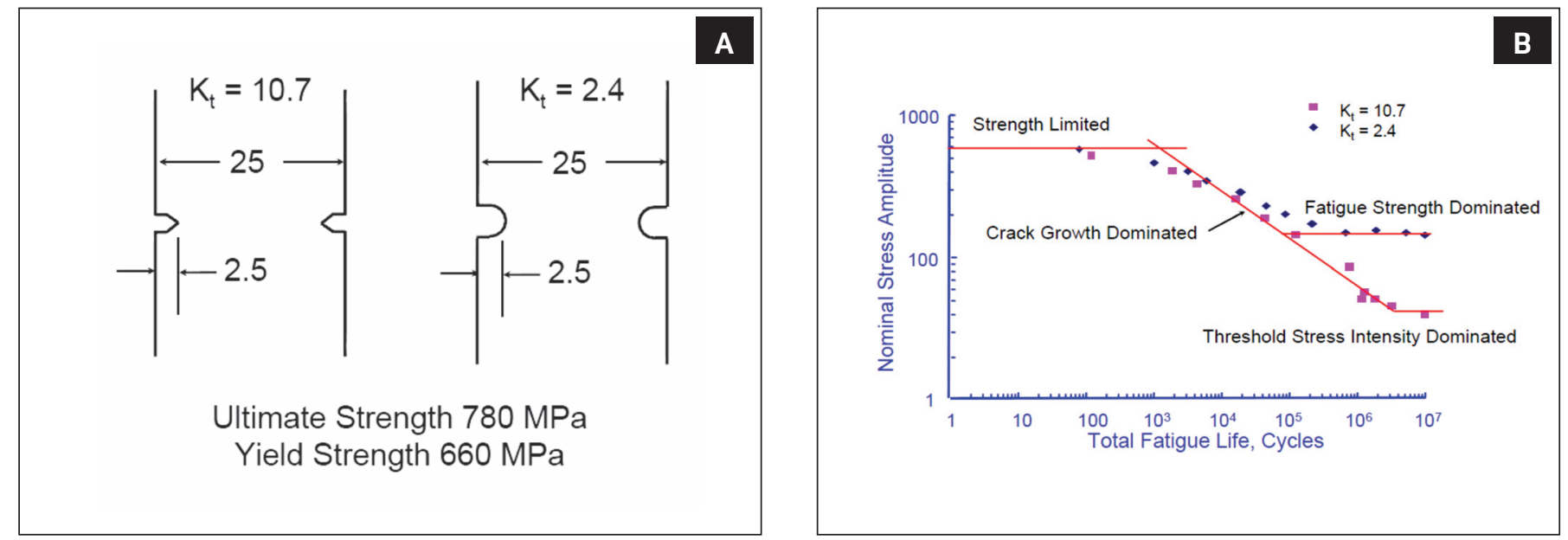

Fig. 6 - Comparison of fatigue test results presented in S-N curve forms (log-log scale): A - Notch geometry and stress concentration factors $\left(K_{t}\right) ; B$ - comparison of $S-N$ curves and fatigue strengths.
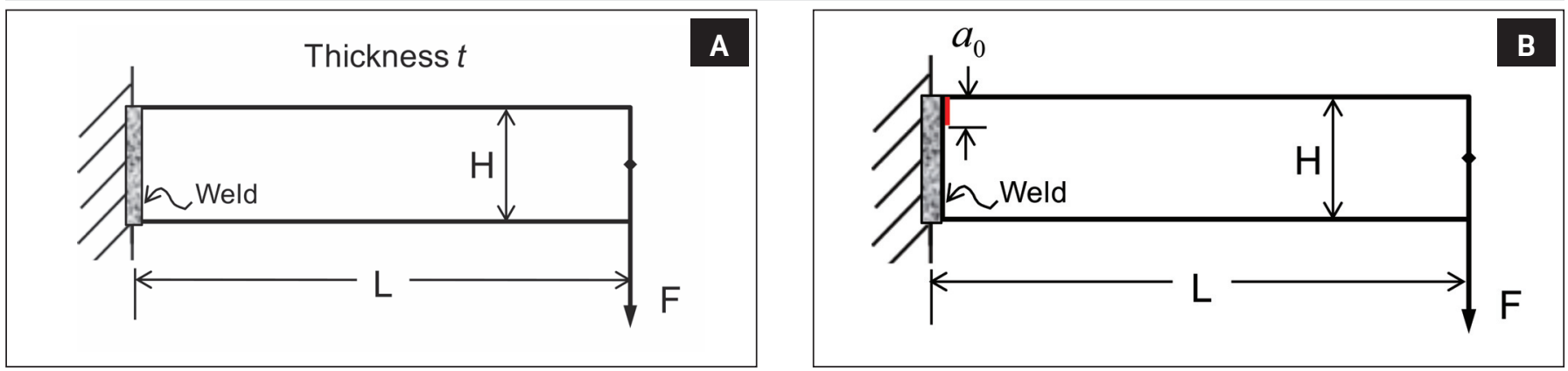

Fig. 7-Illustration of conventional strength-based design and fracture mechanics based design methods: A - Conventional beam theory based design; $\mathrm{B}$ - fracture mechanics based design considering a small crack-like imperfection $\left(a_{0}\right)$.

\section{A Traction Structural Stress K Solution Method}

\section{Mesh Insensitive Traction Stress Method}

Over the past decade, a traction stress calculation procedure (Refs. 2, 15-17) has demonstrated its ability to provide a simple and effective stress intensity factor $(\mathrm{K})$ estimation for complex joints, in addition to its mesh insensitivity in charactering stress concentrations. The traction stress definition (Fig. 11) is based on fracture mechanics considerations. By considering a hypothetical crack plane (e.g., a line cut along A-A in Fig. 11A or a curvilinear surface cut along C-C in Fig. 11B) at the weld toe, the Mode I stress intensity factor $\mathrm{K}_{\mathrm{I}}$ is determined by the normal traction component $\sigma_{s}$, Mode II $\mathrm{K}_{\mathrm{II}}$ is determined by the transverse shear component $\tau_{z}$, and Mode III $K_{\text {III }}$ by the in-plane shear component $\tau_{s}$ (Refs. 18-20). For most applications, only $\sigma_{s}$ and $\tau_{s}$ are dominant, and $\tau_{z}$ is typically negligible. The traction stress procedures are given in a number of papers and in the 2007 ASME FFS-1 Fitness-for-Service, Section VIII Division 2 Code and 2007 API-579-1 (Ref. 2).

With the traction stress method, the traction stress component of interest at any given through-thickness cross section cuts along an arbitrary weld line can that be calculated with a great deal of consistency, or referred to as mesh insensitivity. One example is summarized in Fig. 12. The nor- mal traction stresses calculated along a curvilinear surface cut, along the weld toe on the chord, are also given in Fig. $12 \mathrm{C}$. The traction stress is normalized by applied nominal stress on the brace. The stress concentration factor (SCF) results are clearly shown being mesh size insensitive as element size varies from 0.25 to about $2 t$ ( $t$ is chord wall thickness), as shown in Fig. 12B.

\section{Rapid K Solution Technique}

In addition to its mesh insensitivity in traction stress calculation for complex joints, the properties of the traction stress method greatly simplify stress intensity factor solution. As illustrated in Fig. 13, the very definition of traction (Fig. 11) is consistent with the far-field stress definition $\left(\sigma^{\infty}\right)$ in fracture mechanics. Therefore, the traction stress calculation process can be viewed as a stress transformation process from an actual complex joint in a structure under arbitrary loading to a simple fracture problem, in which the complex loading and geometry effects are captured in the form of membrane and bending. As a result, $K$ for any crack size along the weld can be estimated by using the existing $\mathrm{K}$ solution for a simple plate fracture mechanics specimen subjected to both membrane tension and bending, by considering either an edge crack or a surface elliptical crack.

The detailed derivations and validations can be found in Ref. 3 For demonstration purposes, Fig. 14 shows the vali- 


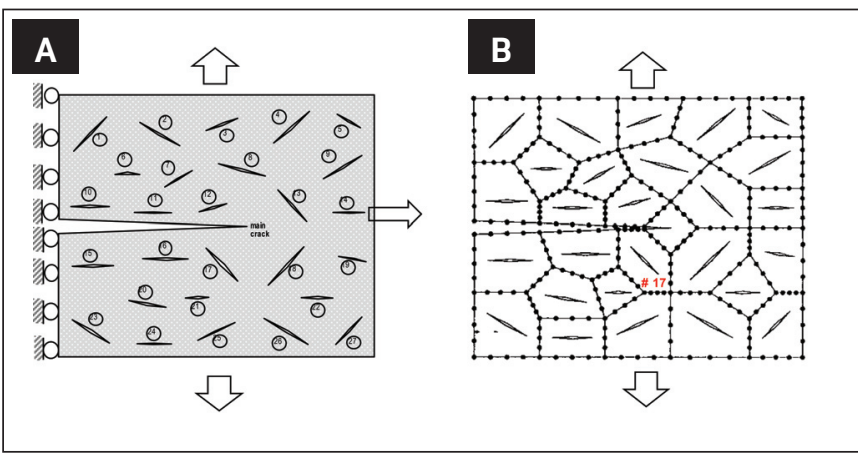

Fig. 8 - Application of a HPE method in evaluation of a cracked body (2D) containing a total of twenty microcracks: A - Problem definition; $B-$ HPE model.

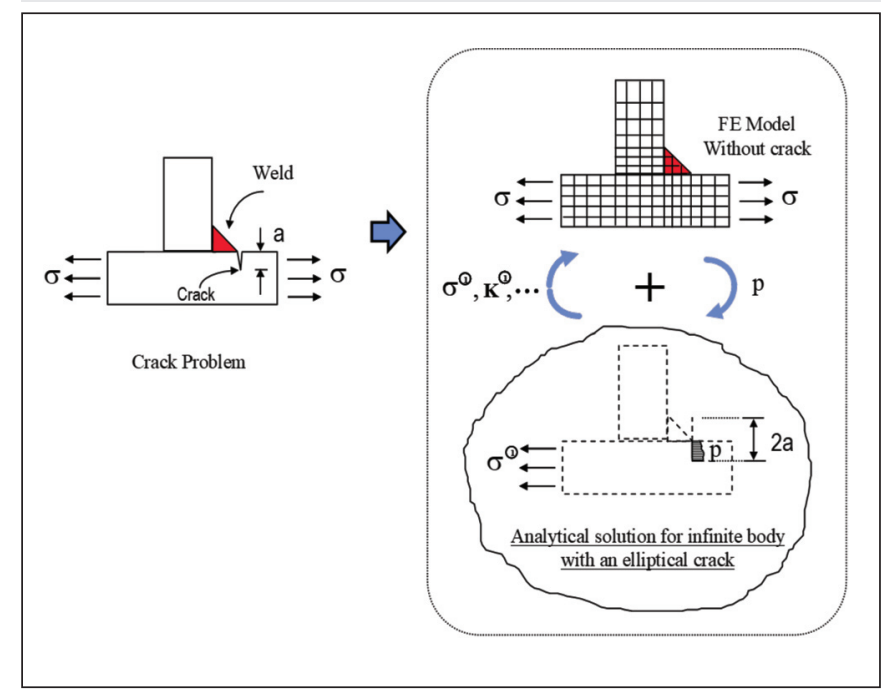

Fig. 10 - Illustration of FEAM.

dation for considering both an edge crack and a semielliptical surface crack situated at the weld toe in a T fillet weld. In Fig. 14A and B, attention should be given to the case labeled as "W/ notch effects" and its comparison with the solutions represented by symbols, which were given by Glinka et al. (see discussions given in Ref. 3) based on a weight function method. Other solutions (dashed lines) are based on other forms of approximation methods and plotted here only for comparison purpose. It can be seen that the traction stress based $\mathrm{K}$ solution compares well with the weight function solution over the entire crack size range considered. The same can be said about the traction stress based $\mathrm{K}$ solutions corresponding to semielliptical crack - Fig. 14C.

\section{Quantitative Quality Acceptance Criteria}

\section{Aluminum Alloy Resistance Spot Welds}

Figure 15 shows typical spot weld cross section macrographs exhibiting a significant level of pores and microcracks. After some preliminary examination, the HPE model shown in Fig. 15B was constructed containing a total of six pores of variable size, orientation, and location. After a total of 242 parametric (242 cases) analyses over these param-

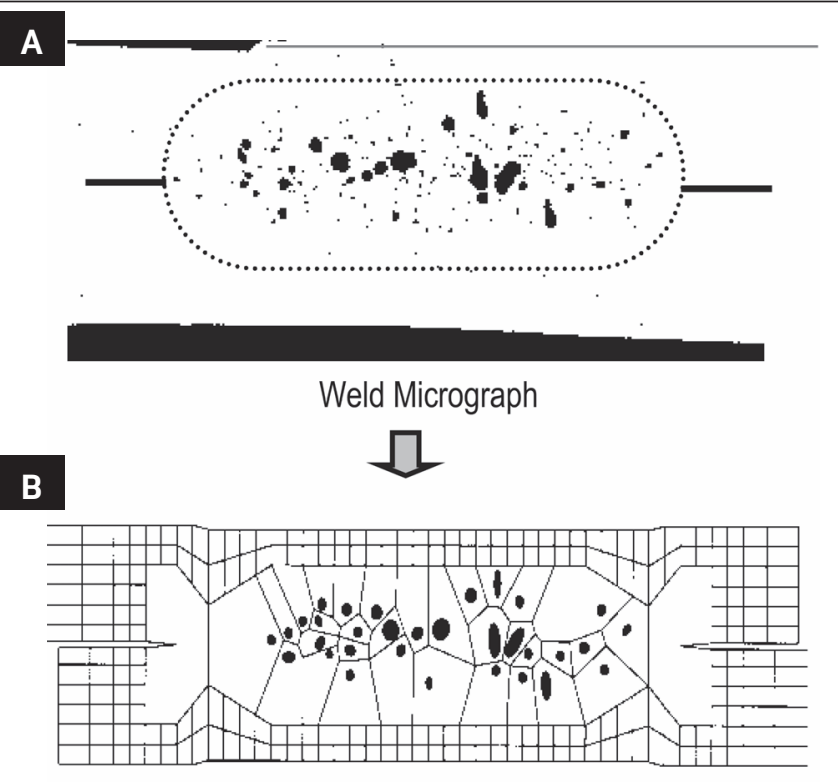

Fig. 9 - Application of a HPE method in evaluation of aluminum spot weld containing randomly distributed pores: $A-$ a representative spot weld cross section; B - HPE model.
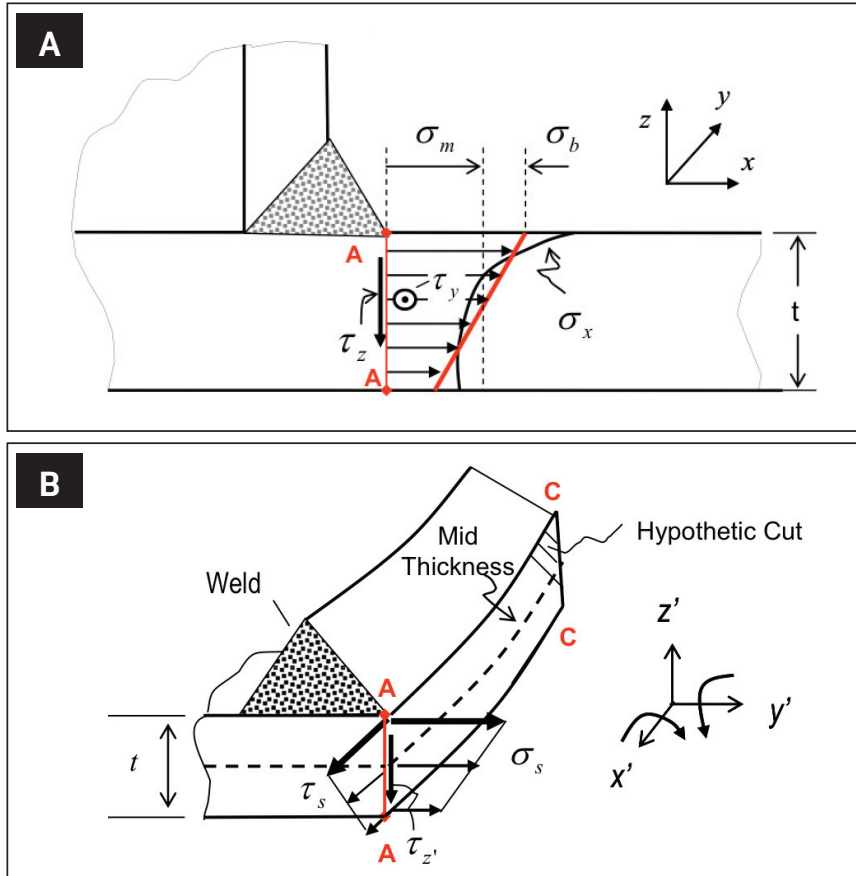

Fig. 11 - "Free-body cut" illustration of mesh-insensitive structural stress method: $A-2 D$ cross section cut along Line $A-B ; B-$ curvilinear area cut between $A-A$ and $C-C$.

eters, a total of four characteristic distributions (or cases) were found (Fig. 16) under the two most severe loading scenarios - lap tension (also referred to as coach peel) and lap shear.

The fracture mechanics analysis results corresponding to the four characteristic cases in Fig. 16 are summarized in Fig. 17 , normalized by the stress intensity factor for the main interfacial crack $K_{0}$. As can be seen in Fig. 17, as long as defects 

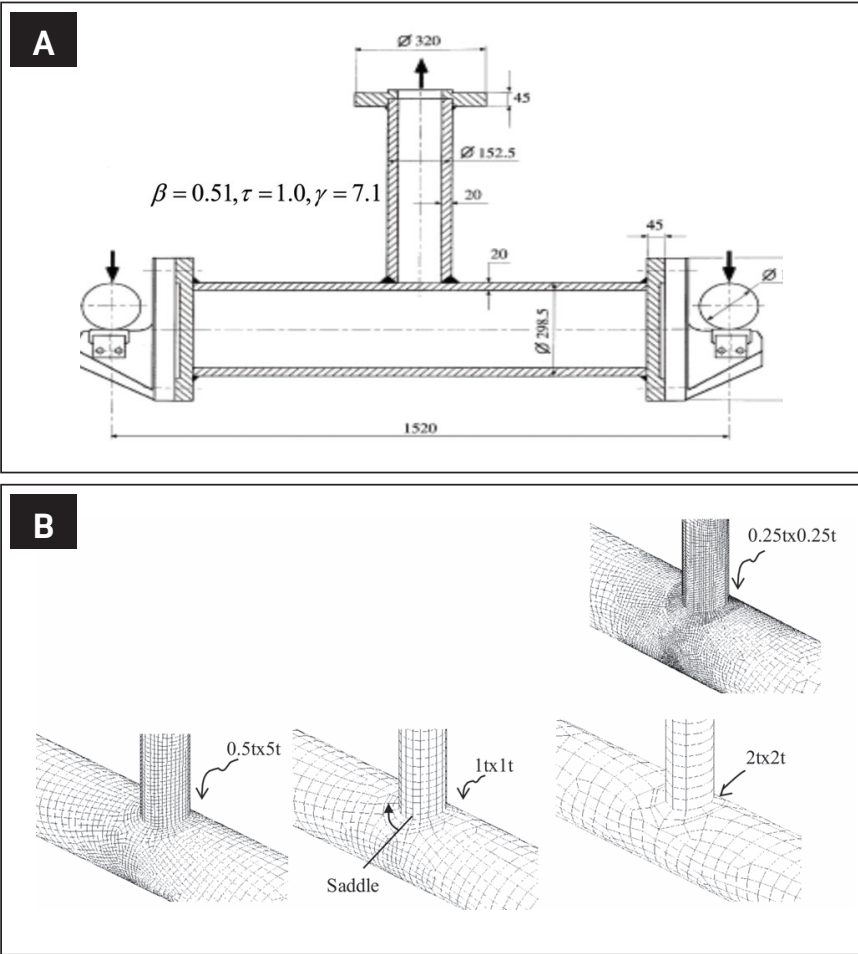

C

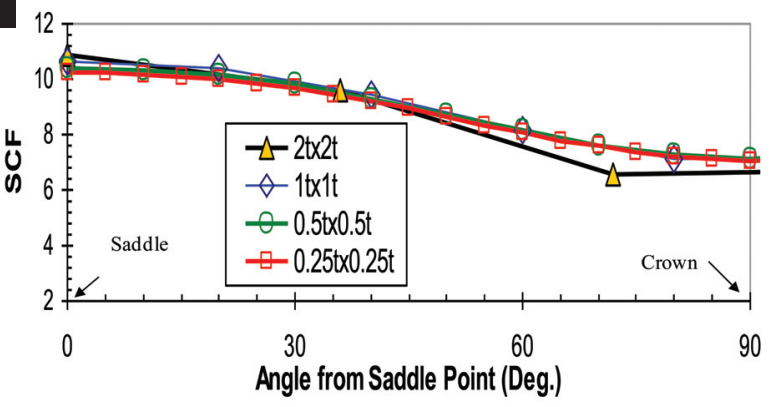

Fig. 12 - Demonstration of mesh-insensitivity of traction structural stress along weld toe on chord in a tubular $T$ joint: $A-$ Overall $T$ joint geometry and loading conditions; $B-F E$ models with different element sizes; $C$ - comparison of structural stress results calculated along weld toe.

are confined within the middle of the weld nugget, approximately within $50 \%$ of the nugget radius, there exists no noticeable detrimental effects. As a result, the first two types (to the left of Fig. 17A and B) are considered equivalent to perfect welds (i.e., without any pores).

The results in Figs. 16 and 17 also provide an effective means for performing validation testing by grouping specimens in terms of porosity distribution types, rather than based on specific defect size and location, (such as those in Fig. 16 , which are practically impossible to repeatedly reproduce in practice. Such a validation testing effort is summarized in Fig. 18. As long as the $50 \%$ nugget radius criterion is satisfied, Fig. 18 shows that the corresponding S-N test data form essentially the same scatter band, indicting no detrimental effects of pores as long as they are within the $50 \%$ radius of the weld nuggets. For cases in which pores are widespread or near the nugget edges, there exists a significant degradation of fatigue

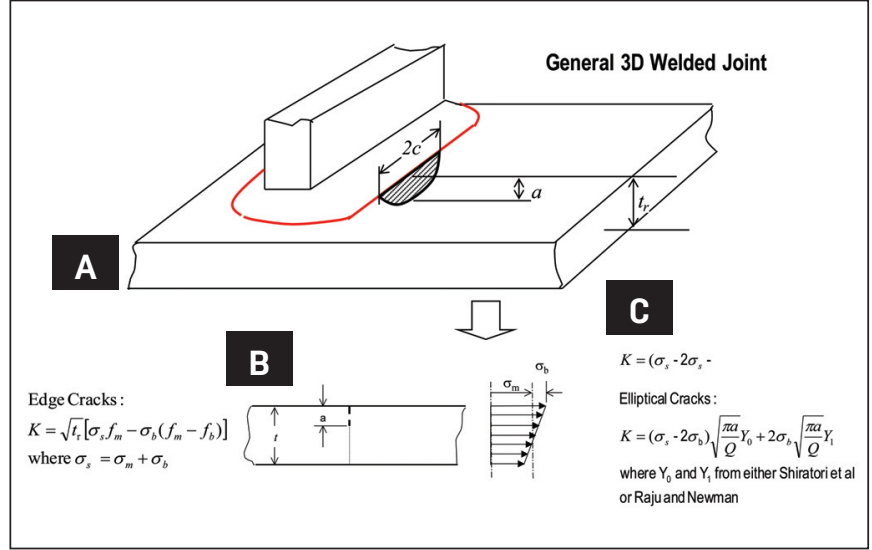

Fig. 13 - Traction structural stress based mapping for rapid stress intensity factor $(K)$ calculation in complex welded components: $A-A$ 3D plate T joint; $B$ - edge crack solution (2D); C - semielliptical surface crack solution.

performance, e.g., for the cases labeled with "edge pores" shown in Fig. 18B. As a result, a shop floor implementation at a major automotive company is illustrated in Fig. 19, representing radiographies of periodic inspection results.

\section{Metallic AM Parts}

As illustrated in Fig. 4, in AM parts, two types of discontinuities are of concern as far as fatigue performance is concerned: (a) surface roughness and surface defects and (b) internal defects.

\section{Surface and Subsurface Defects}

Even under machined and polished surface conditions, the round bar specimens (Ti-6-4) still showed significantly lower fatigue performance than wrought conditions - Fig. 20 . This is because although overall surface roughness can be improved by machining and polishing, the subsurface discontinuities shown in Fig. 4 are exposed as surface discontinuities. Such effects are clearly illustrated, as summarized in Ref. 21, by detailed examination at a local machined and polished V notch tip of fatigue test specimens - Fig. 21 (Ref. 21). Here, geometric features are not that different from typical welded joints, say at the weld toe position, as shown in Fig. 1A.

The effectiveness of the mesh insensitive traction structural stress method previously described (see Figs. 11 and 12) has been demonstrated effective in collapsing fatigue test data into a single narrow band for welded joints (Ref. 2). Given the similarities in notch root discontinuities shown in Fig. 21, it is conceivable that the mesh insensitive method could work equally well for correlating fatigue test data for metallic AM parts if different machined notch geometries are considered. Such test data were recently published by Solberg and Berto (Ref. 21), as summarized in Fig. 22 for which typical notch tip surface conditions are given in Fig. 21. A total of four notch types are considered as shown in Fig. 22A. The test data are shown in Fig. 22B in terms of nominal stress range in log-log scale, showing four distinct trend lines. By using the traction stress method previously 


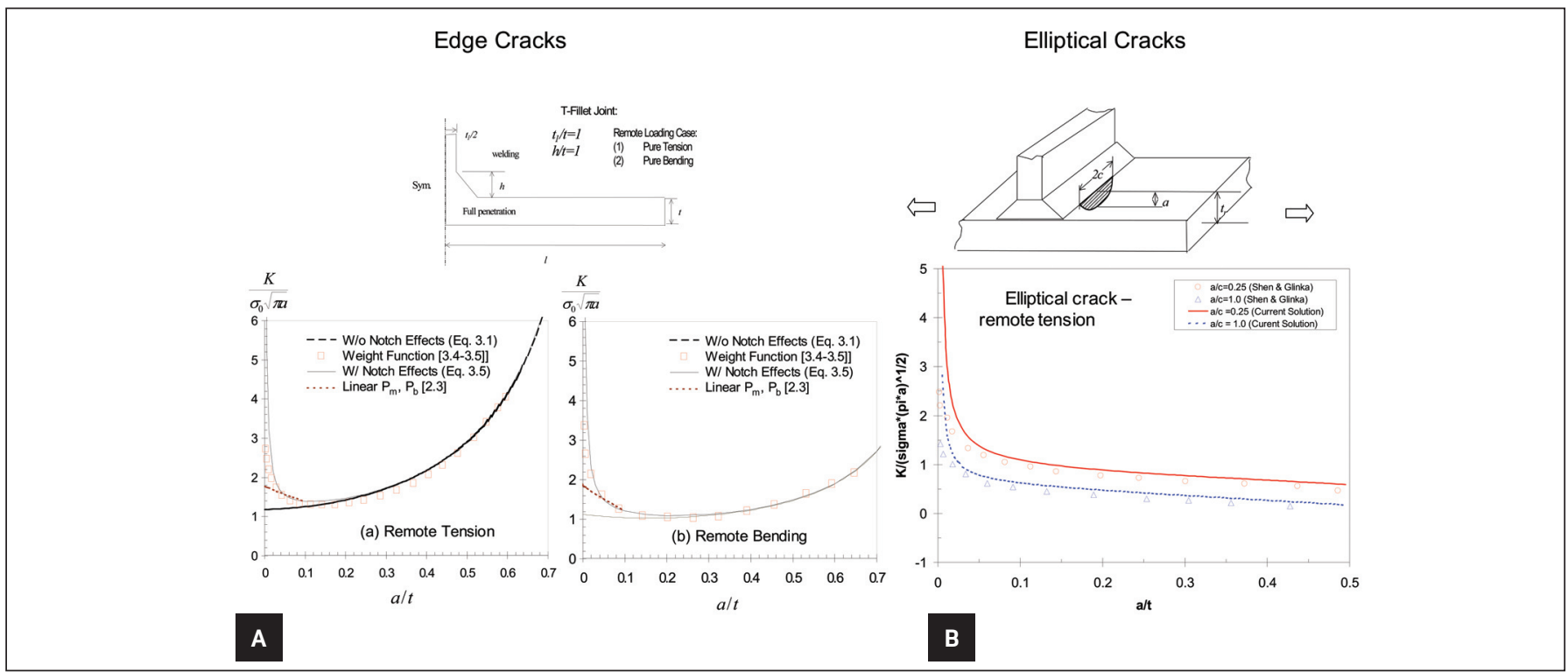

Fig. 14 - Validation of traction stress based stress intensity factor solutions for a T joint: A - Edge crack; B - semielliptical crack.

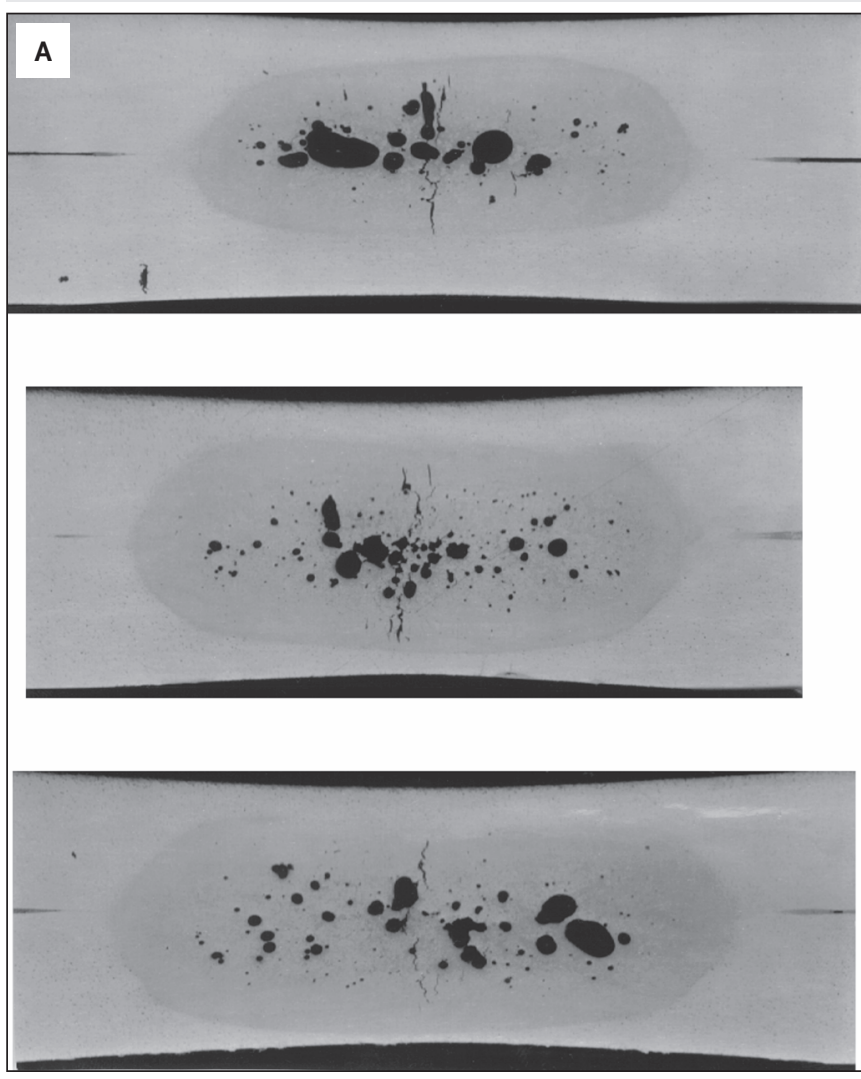

described, the traction stress based SCFs are then calculated using the FE models shown in Fig. 22C. It should be noted that the conventional local stress based SCF or $K_{t}$ doesn't exist due to the ill-defined notch geometries shown in Fig. 21, while the traction stress based SCF can be computed in a mesh insensitive manner, thanks to its equilibrium basis with respect to the cross section cut plane (i.e., fatigue crack propagation plane). The resulting $\mathrm{S}-\mathrm{N}$ data correlation in Fig. 22D shows a significant improvement over Fig. 22B, suggesting a good transferability S-N test data among differ-

\section{B}

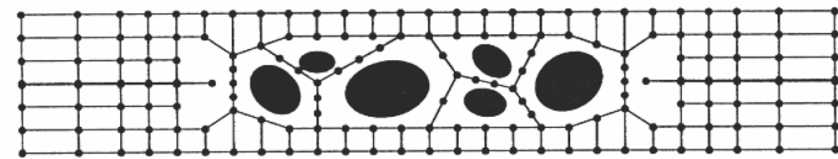

Fig. 15 - HPE model for modeling distributed pores in aluminum spot welds: $A$ - Representative macrographs of spot welds showing distributed pores; B - HPE model for representing effects of pores on stress intensity factor of interfacial slit modeled as a crack.

ent notch geometries. Additional results are presented in (Ref. 22), including detailed discussions on computational procedures for SCF calculations.

The traction structural stress method has the advantage of simplicity since it is mesh size insensitive. It would be useful to compare with a more elaborate method developed specifically for correlating the same data shown in Fig. 22 (Ref. 21) in which local strain energy change with respect to a control volume surrounding the notch root. Such a comparison is given in Fig. 23. Note that in the original plot taken from Ref. 21 (see Fig. 23B here), the test data corresponding to "smooth" were not included in Fig. 23B. With the same three sets of test data taken directly from Fig. 22C, in terms of traction stress range, are plotted in Fig. 23A. It can be seen that the correlation based on traction stress range in Fig. 23A seems better than that shown in Fig. 23B, in addition to the method's simplicity. The key reason for the good correlation in terms of traction stress lies in the fact that the traction stress was specifically developed for treatment of crack propagation dominated fatigue lives, e.g., in welded joints. The similarities between AM parts (see Fig. 21) and welded joints (see Fig. 1A) seem obvious. 


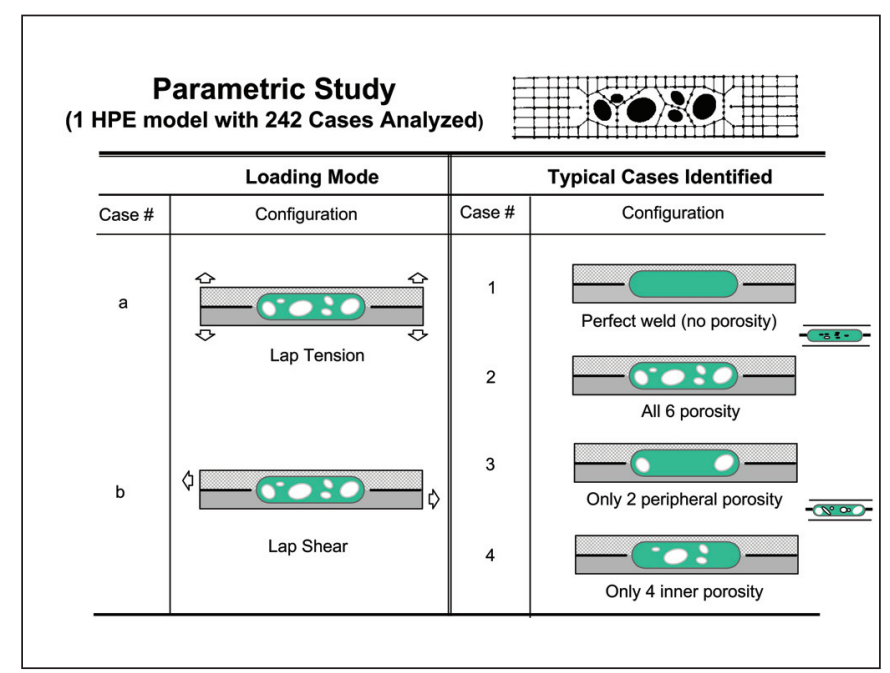

Fig. 16 - Characteristic porosity distributions identified by parametric analysis using HPE model given in Fig. 15B.

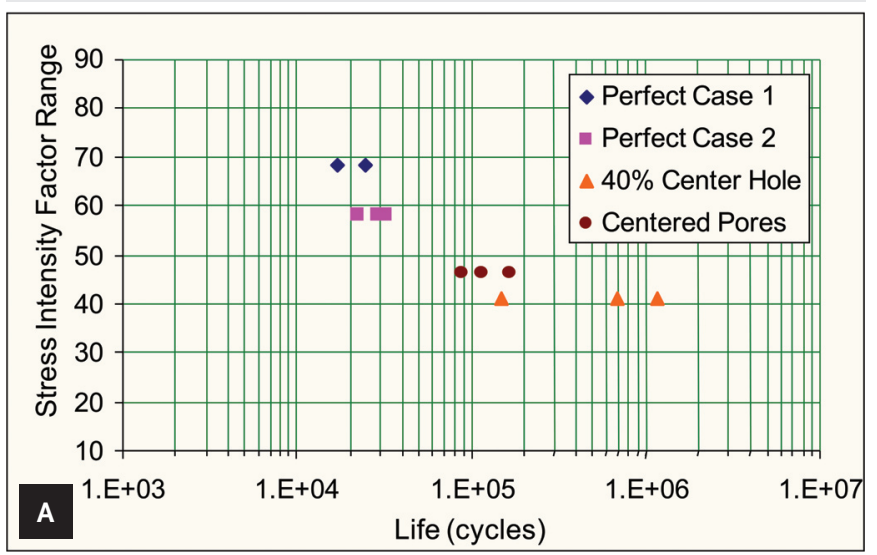

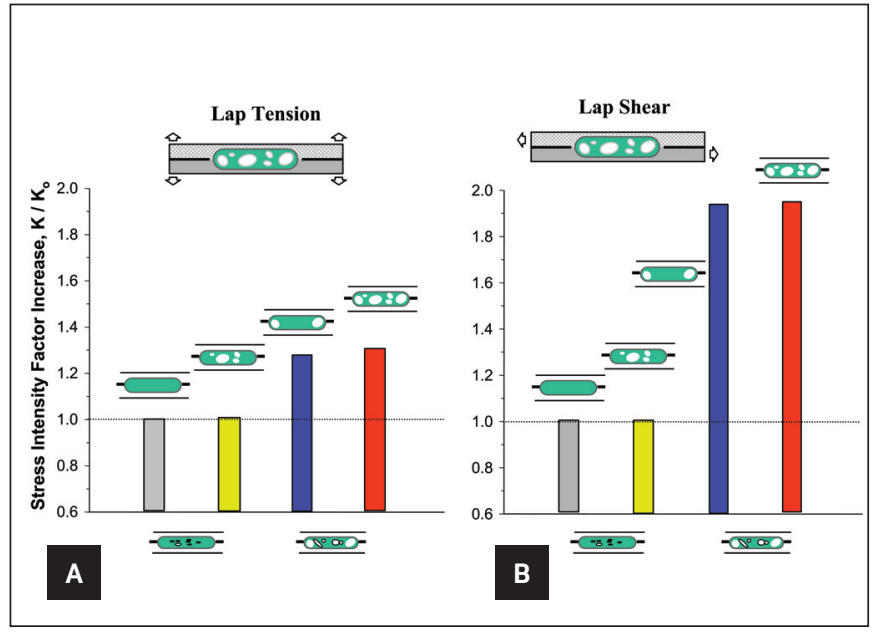

Fig. 17 - Stress intensity factor results corresponding to characteristic distribution types given in Fig. 16: A - Lap tension (i.e., coach peel); B - lap shear.

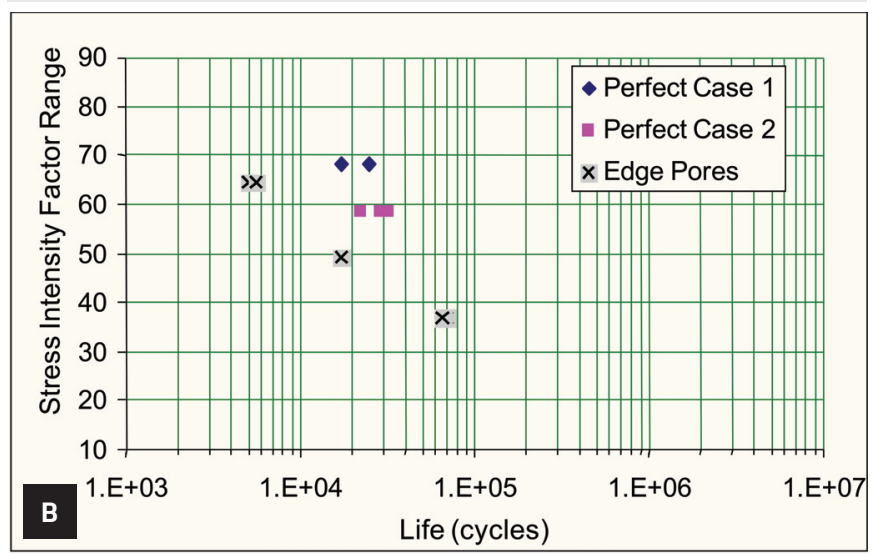

Fig. 18 - Fatigue test results for validating the computational results given in Fig. 17, based on characteristic porosity distribution types given in Fig. 16: A - Cases 1 and 2; B - Cases 3 and 4.

\section{Internally-Distributed Defects}

Consider the randomly distributed indications shown in Fig. 4B. A finite element alternating model previously discussed was generated as shown in Fig. 24 by considering a transverse cross section normal to bar's longitudinal axis (Fig. 24A). Within such a cross section, any number of elliptical crack-like defects (with minor axis represented as $a$ and major axis as $b$ - Fig. 24A) can be analytically defined for examining stress intensity factors along a crack front under given loading conditions. For the present study, three cases are investigated: a single elliptical crack-like defect (Fig. 24B); two coplanar elliptical cracks (Fig. 24C); and three coplanar elliptical cracks (Fig. 24D). Note that the single crack case shown in Fig. 24B is for evaluating crack location effects by changing the crack position from the center of the bar to the edge. This represents a unique advantage of the FEAM technique, for which one FE mesh (Fig. 24A) is all that is needed for examining both the crack location effect (Fig. 24A) and the effects of multiple crack interactions (Fig. 24C and D). Due to space limitation, we only consider remote tension loading conditions i.e., tensions along $\mathrm{z}$ axis) here. For other loading conditions, results and conditions are given in Ref. 22. The ellipses with dashed lines in Fig. $24 C$ and D represent the equivalent crack size stiputed in FFS Codes and Standards, e.g., see API 579 (Ref. 6) or BS 7910 (Ref. 7).

The stress intensity factor $(\mathrm{K})$ results for single elliptical crack case are shown in Fig. 25. Note the all computed $\mathrm{K}$ results are normalized by $\sigma_{0} \sqrt{\pi a}$ where $\sigma_{0}$ represents remote applied tension stress. At a given crack position, the maximum $\mathrm{K}$ occurs at $\theta=90 \mathrm{deg}$, corresponding to the minor axis position as shown in Fig. 25A. As crack position is moved closer to the bar edge, i.e., $d / R>0.9$, the maximum $\mathrm{K}$ shows a rapid increase. At $d / R=1$, the elliptical crack becomes a semielliptical surface crack, representing the most severe defect condition.

Two coplanar elliptical cracks are considered in Fig. 26. The purpose is to evaluate the existing equivalent crack size (see dashed ellipse) criterion when the two crack-like defects are situated close to each other with a spacing of $s \leq 2 a$. The stress intensity factor results along the two crack fronts are shown as Crack 1 (C1) and Crack 2 (C2) in Fig. 26. Separate FEAM analyses were also performed for single equivalent 

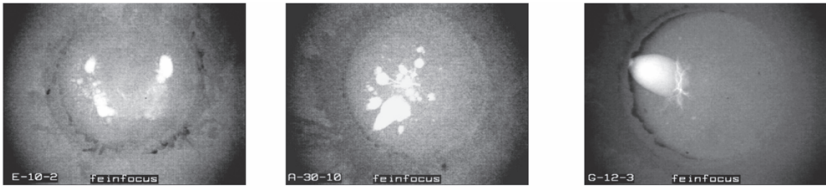

Reject!
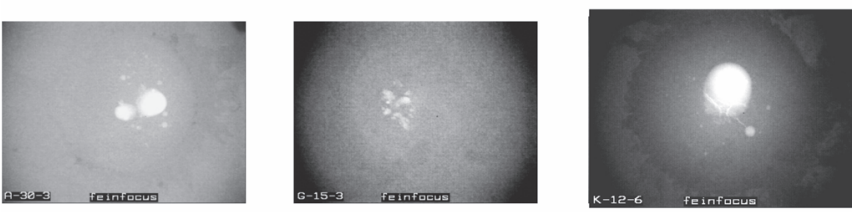

Accept

Fig. 19 - Shop floor implementation.

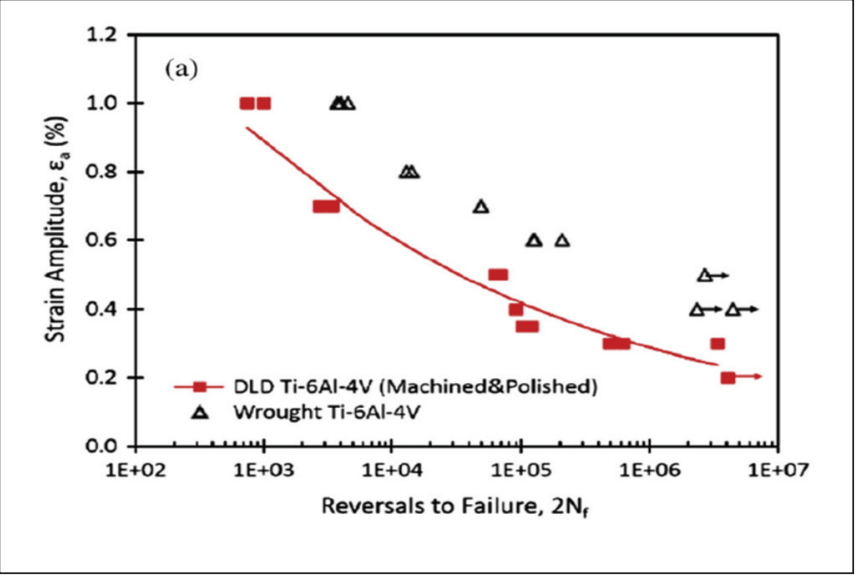

Fig. 20 - Strain-life results of 3D printed titanium alloy Ti-6-4 bar specimens (Ref. 5).

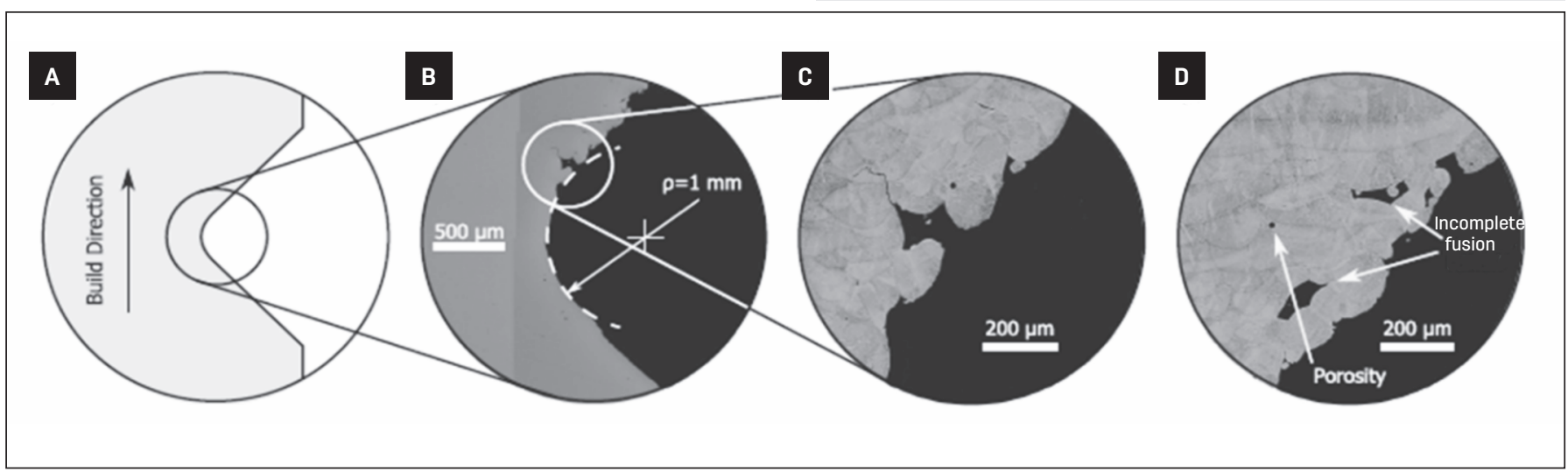

Fig. 21 - Notch geometry details of a V-notched fatigue specimen made by a 3D print process (Ref. 21).

crack corresponding to $s=0.5 a, 1 a, 2 a$, respectively. All these $\mathrm{K}$ results are compared in Fig. 26B-D. The results show that any interactions between the two coplanar cracks becomes insignificant when their spacing becomes larger than $1 a$ or $s=1 a$ and that existing $s \leq 2 a$ criterion in today's codes and standards, e.g., Refs. 6 and 7, seems excessively conservative, particularly for AM applications (see Fig. 4). The same can be said about three coplanar cracks, as shown in Fig. 27. The excessive conservatisms associated with existing defect interaction criteria shown in Figs. 26 and 27 (see the results labeled as "equivalent") often lead to unnecessary weld repairs that can cause unintended consequences, e.g., high biaxial or triaxial residual stresses (Refs. 23 and 24).

\section{Conclusion}

After a brief overview of some of the recent needs for developing quantitative defect acceptance criteria in supporting structural lightweighting and additive manufacturing, some of the recent developments in applied fracture mechanics as well as robust computational methods are highlighted. The emphasis is given to their engineering applications for enabling the development of quantitative defect acceptance criteria for ensuring structural integrity and cost-effectiveness in engineering construction. A series of case studies are presented, spanning from aluminum spot welds to metallic AM parts. The following may be considered as the key messages of this paper:

1) Quantitative quality acceptance criteria supported by fracture mechanics principles and recent computational modeling techniques become increasingly important for effectively supporting today's increasingly stringent lightweighting requirements.

2) Existing defect interaction criteria seem excessively conservative in dealing with randomly distributed discontinuities often occurring in joining lightweight metals, e.g., aluminum alloys and metallic AM parts. The quantitative results presented in this paper suggest that these criteria in relevant codes and standards should be updated by taking advantages of recent developments in some of the computational methods.

3) In today's quality control, industry tends to put more emphasis on acquiring high-tech and high-resolution nondestructive techniques that have been advancing at a much more rapid pace than our understanding of the structural significance of various forms of manufacturing defects, particularly those from newer joining and AM processes. The hope is that this paper has provided rationales for the importance of taking a parallel path for establishing what to look for and where to look when using these advanced NDE techniques, as well as how to interpret a defects' significance to structural integrity. 

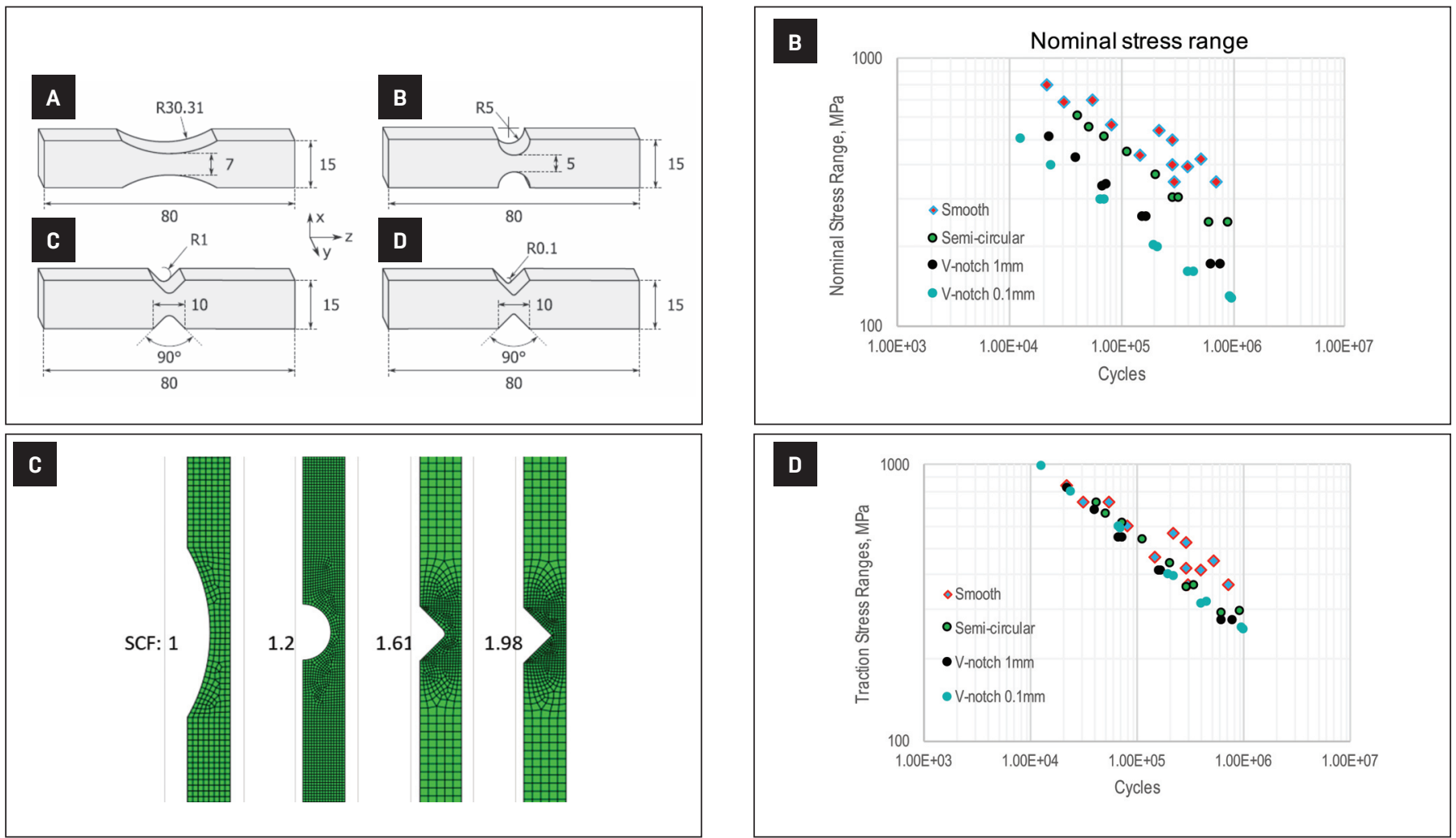

Fig. 22 - Analysis of fatigue test results of notch geometry effects on fatigue behaviors in 3D printed metallic specimens: A Specimen geometry; B - nominal stress range vs. cycles to failure; C - FE models for computing SCFs; D - traction stress.

\section{A}

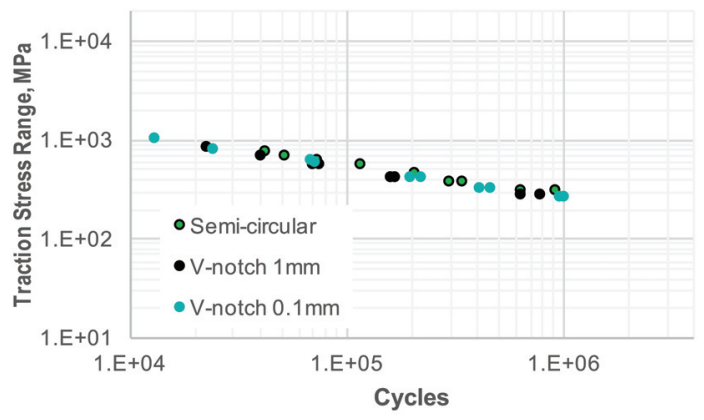

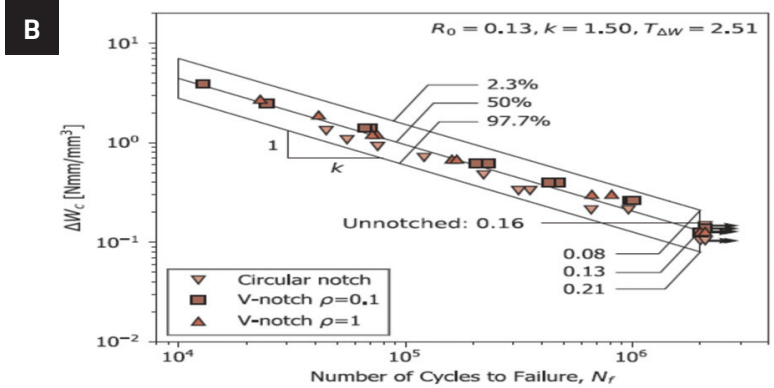

Number of Cycles to Failure, $N_{r}$

Fig. 23 - Comparison of fatigue test data taken from Fig. 22 between traction stress range and a local energy based fatigue parameter: A - Traction stress range; B - local energy parameter taken from (Ref. 21).

\section{Acknowledgments}

The author acknowledges the financial support of some of the work reported in this paper through a grant from CRRC Qiqihar Rolling Stock Co. Ltd. at the University of Michigan (Grant No.: N025456). The author would like to express special thanks to CRRC Qiqihar project representative Dr. Xiangwei Li for his technical support and encouragements during the preparation of this article.

\section{References}

1. Dong, P. 2017. Defect assessment, University of Michigan NA 513 Coursepack.
2. Osage, D. A., Dong, P., and Spring, D. 2018. Fatigue assessment of welded joints in API 579-1/ASME FFS-1 2016-existing methods and new developments. Procedia Engineering (213): 497-538. DOI: 10.1016/j.proeng.2018.02.049

3. Dong, P., Hong, J. K., Osage, D. A., Dewees, D. J., and Prager, M. 2010. The master SN curve method: An implementation for fatigue evaluation of welded components in the ASME B\&PV code, Section VIII, Division 2 and API 579-1/ASME FFS-1. Welding Research Council Bulletin 523.

4. Dong, P., and Hong, J. K. 2004. Fracture mechanics treatment of residual stresses in defect assessment. Welding in the World 48(5-6): 19-27. DOI: 10.1007/BF03266428

5. DebRoy, T., Wei, H. L., Zuback, J. S., Mukherjee, T., Elmer, J. W., Milewski, J. O., and Zhang, W. 2018. Additive manufacturing of metallic components-process, structure and properties. Progress in Materials Science 92: 112-224. DOI: 10.1016/j.pmatsci.2017. 10.001 


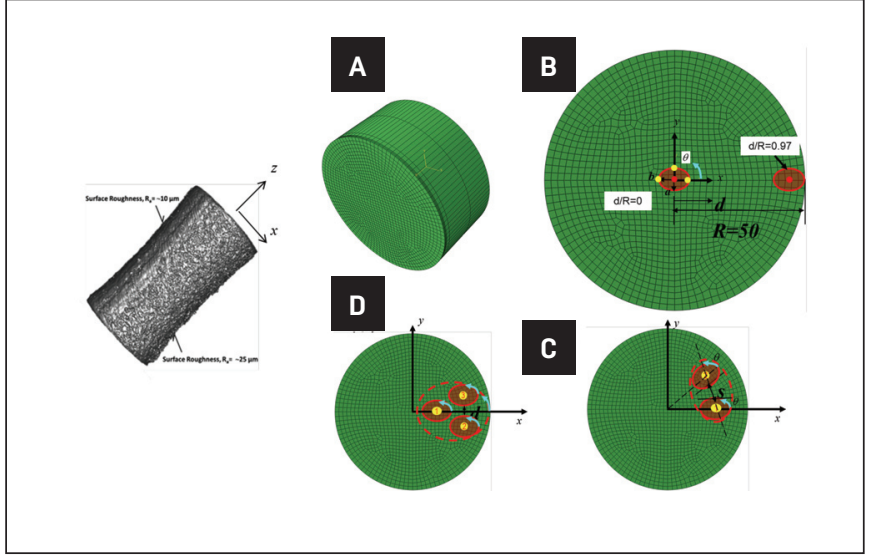

Fig. 24 - FEAM model for examining defect position effects and multi-defect interaction effects: $A$ - FEA model; B centrally-located elliptical internal defect; $C$ - two coplanar defects; $D$ - three coplanar defects.
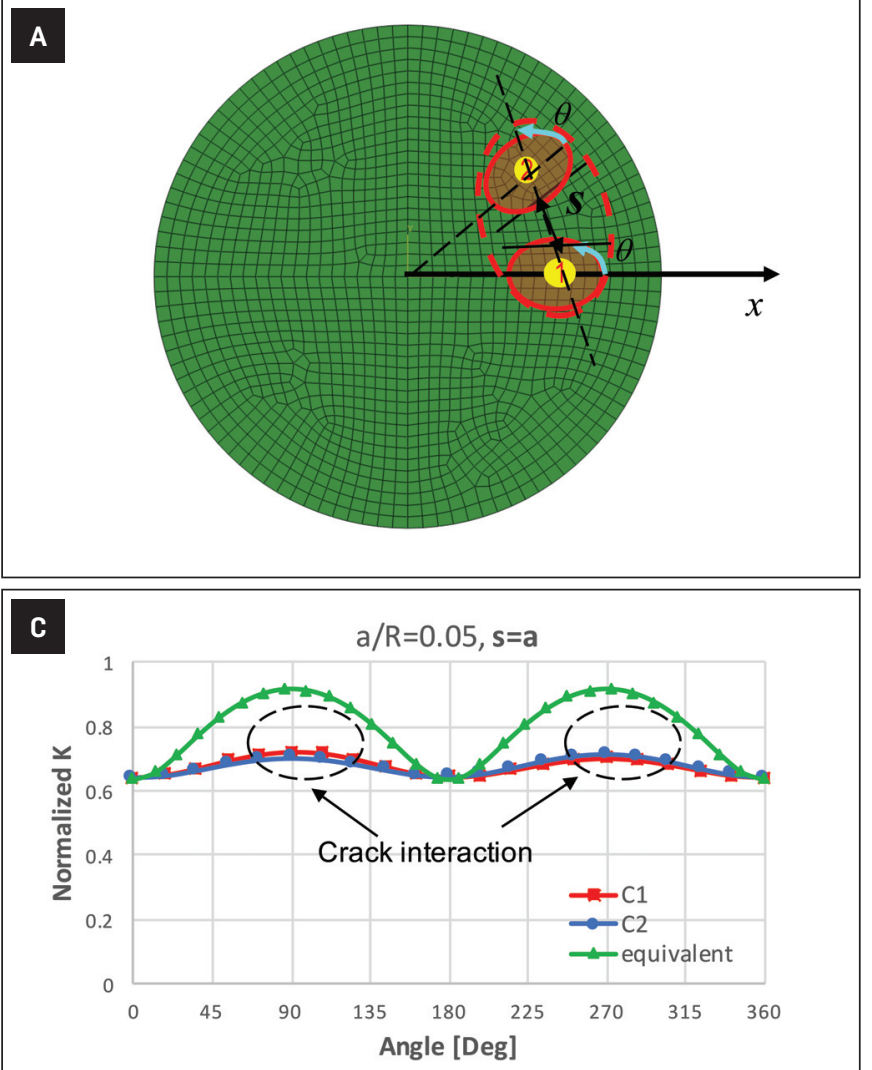

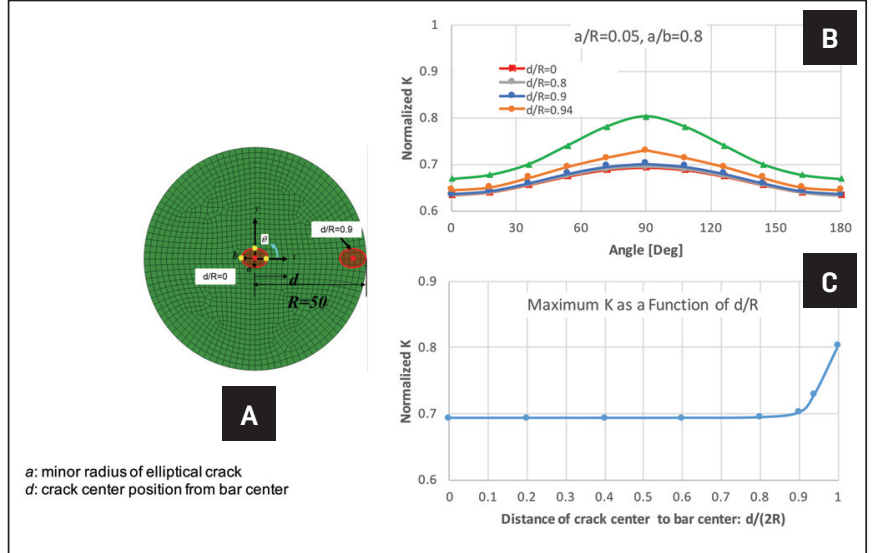

Fig. 25 - Stress intensity factor as a function of defect location - one defect: A - Centrally located defect vs. near-edge defect; $B$ - stress intensity factor distribution along defect front; $C$ - maximum stress intensity factor as a function of defect location.

B

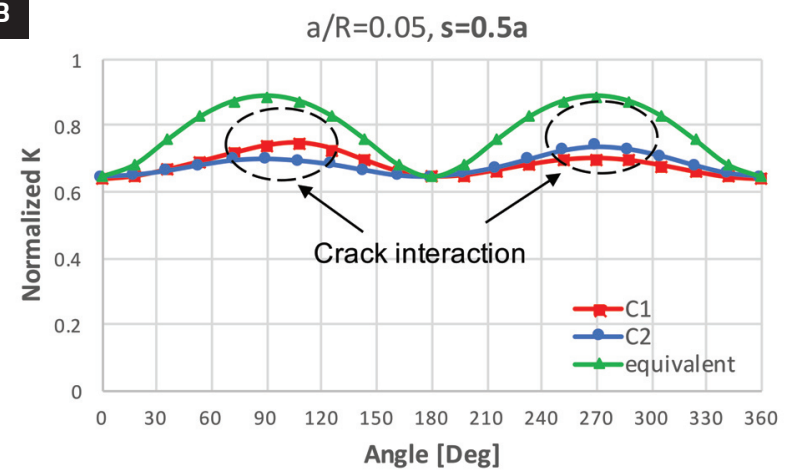

D

$a / R=0.05, s=2 a$

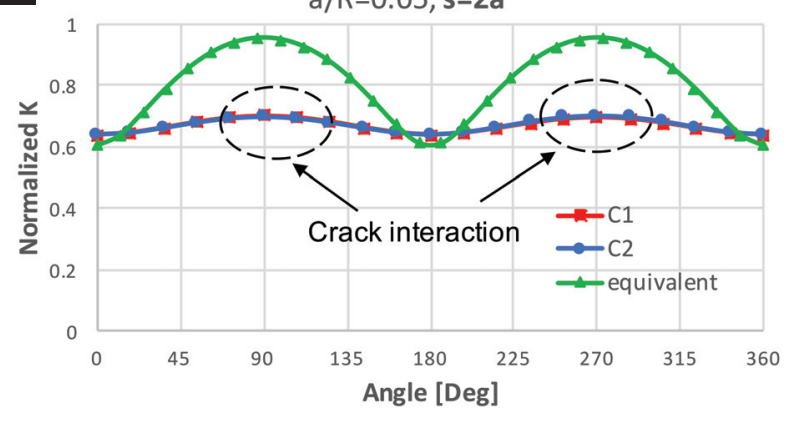

Fig. 26 - Stress intensity factor as a function of defect location - two coplanar defects and equivalent defect (dashed line): A - Positions of defects studied; $B$ - stress intensity factor distribution along defect fronts with defect spacing $\mathrm{s}=0.5 \mathrm{a}$; $\mathrm{C}-\mathrm{stress}$ intensity factor distribution along defect fronts with defect spacing $\mathrm{s}=\mathrm{a}$; $\mathrm{D}-$ stress intensity factor distribution along defect fronts with defect spacing $s=2 a$.

6. American Petroleum Institue. ASME/API: API 579-1/ASME FFS. 2007. Fitness-for-service, American Petroleum Institute, Houston, Tex.

7. British Standards Institution. 2015. BS 7608: Code of Practice for Fatigue Design and Assessment of Steel Structures. British Standard, London, U.K.

8. Socie, D. F., Dowling, N. E., and Kurath, P. 1984. Fatigue life estimation of notched members. Fracture Mechanics: $15^{\text {th }}$ Symposium. ASTM STP 883, 284-289.

9. Zhang, J., and Katsube, N. 1995. International Journal for $\mathrm{Nu}$ merical Methods in Engineering 38: 1635-1653. DOI: 10.1002/ nme.1620381004

10. Zhang, J., and Dong, P. 1998. A hybrid polygonal element method for fracture mechanics analysis of resistance spot welds 


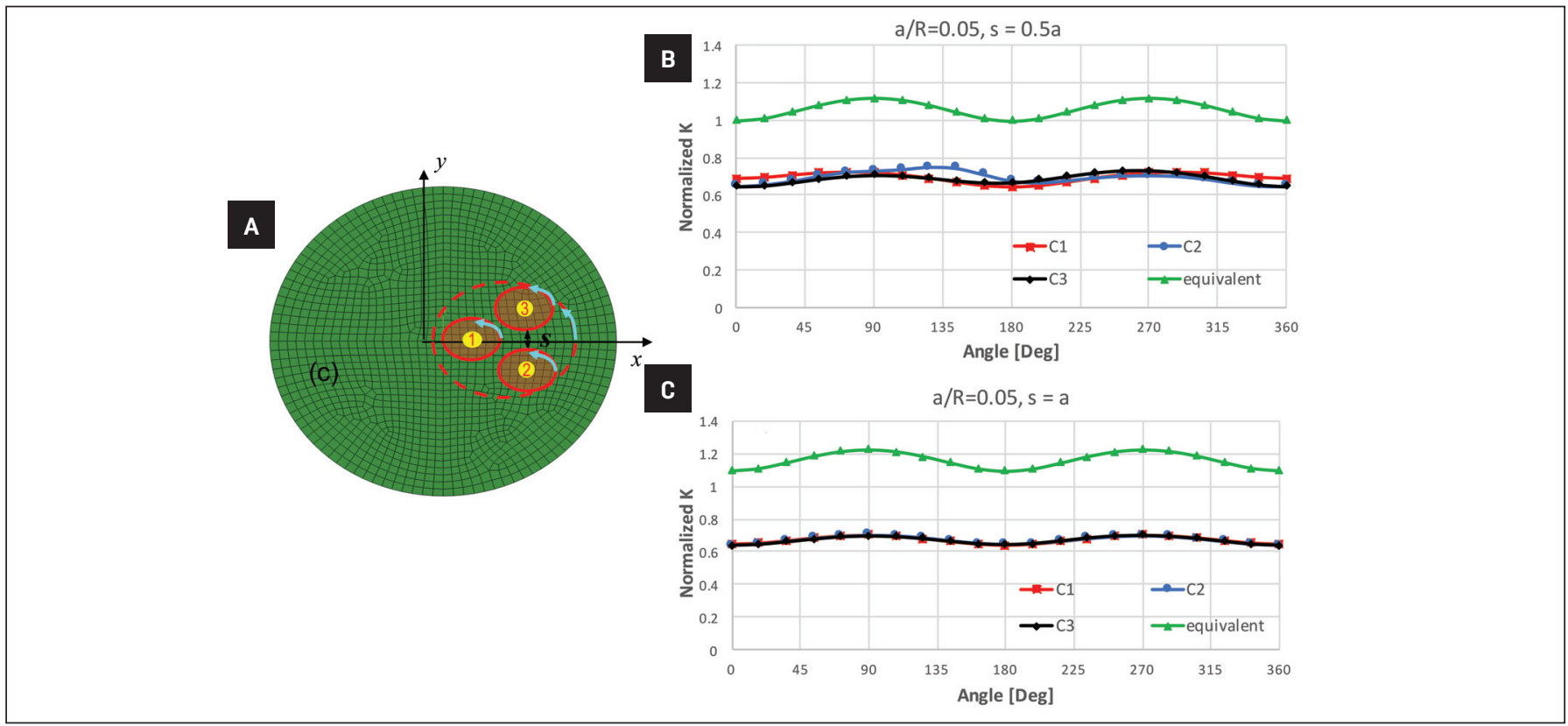

Fig. 27 - Stress intensity factor as a function of defect location - three coplanar crack-like defects and one equivalent defect (dashed line): A - Positions of defects studied; B - stress intensity factor distribution along defect fronts with defect spacing $\mathrm{s}=0.5 \mathrm{a} ; \mathrm{C}$ - stress intensity factor distribution along defect fronts with defect spacing $\mathrm{s}=\mathrm{a}$.

containing porosity. Engineering Fracture Mechanics 59(6):

815-825. DOI: 10.1016/S0013-7944(97)00151-3

11. Dong, P., and Brust, F. W. 2000. Welding residual stresses and effects on fracture in pressure vessel and piping components: A millennium review and beyond. Journal of Pressure Vessel Technology 122(3): 328 and 329. DOI: 10.1115/1.556189

12. Zhang, J., Dong, P., Brust, F. W., Shack, W. J., Mayfield, M. E., and McNeil, M. 2000. Modeling weld residual stresses in core shroud structures. Nuclear Engineering and Design 195(2): 171-187. DOI: 10.1016/S0029-5493(99)00251-4

13. Dong, P. 2008. Length scale of secondary stresses in fracture and fatigue. International Journal of Pressure Vessels and Piping 85(3): 128-143. DOI: 10.1016/j.ijpvp.2007. 10.005

14. Dong, P. 2018. On repair weld residual stresses and significance to structural integrity. Welding in the World 62(2): 351-362. DOI: $10.1007 / s 40194-018-0554-1$

15. Dong, P. 2005. A robust structural stress method for fatigue analysis of offshore/marine structures. J. Offshore Mech. Arct. Eng. 127(1): 68-74. DOI: 10.1115/1.1854698

16. Dong, P., and Hong, J. K. 2004. The master SN curve approach to fatigue evaluation of offshore and marine structures. ASME $23^{\text {rd }}$ International Conference on Offshore Mechanics and Arctic Engineering, 847-855. American Society of Mechanical Engineers Digital Collection. DOI: 10.1115/ OMAE2004-51324

17. Dong, P., and Hong, J. K. 2012. Fatigue of tubular joints: Hot spot stress method revisited. Journal of Offshore Mechanics and Arctic Engineering 134(3): 031602. DOI: 10.1115/1.4005188

18. Dong, P., and Hong, J. 2007. A robust structural stress parameter for evaluation of multiaxial fatigue of weldments. Fatigue and Fracture Mechanics, Vol. 35. DOI: 10.1520/STP45516S

19. Dong, P., Wei, Z., and Hong, J. K. 2010. A pathdependent cycle counting method for variable-amplitude multi-axi- al loading. International Journal of Fatigue 32(4): 720-734. DOI: 10.1016/j.ijfatigue.2009.10.010

20. Mei, J., and Dong, P. 2016. A new path-dependent fatigue damage model for non-proportional multi-axial loading. International Journal of Fatigue 90: 210-221. DOI: 10.1016/j.ijfatigue.2016.05.010

21. Solberg, K., and Berto, F. 2019. Notch-defect interaction in additively manufactured Inconel 718. International Journal of Fatigue 122: 35-45. DOI: 10.1016/j.ijfatigue.2018.12.021

22. Song, S., and Dong, P. 2019. A rapid fracture mechanics evaluation method for assessing structural significance of randomly distributed defects in metallic AM parts.

23. Dong, P., Hong, J. K., Zhang, J., Rogers, P., Bynum, J., and Shah, S. 1998. Effects of repair weld residual stresses on wide-panel specimens loaded in tension. J. Pressure Vessel Technol. 120(2): 122-128. DOI: 10.1115/ 1.2842229

24. Dong, P. 2018. On repair weld residual stresses and significance to structural integrity. Welding in the World 62(2): 351-362. DOI: 10.1007/s40194-018-0554-1

PINGSHA DONG (dongp@umich.edu) is director, Welded Structures Laboratory; professor, Department of Naval Architecture and Marine Engineering; and professor, Department of Mechanical Engineering at the University of Michigan, Ann Arbor, Mich.

Based on the 2019 Comfort A. Adams Lecture delivered November 11, 2019, following the AWS Business Meeting during FABTECH. 